\title{
The Incentive Effects of DRGs' Reimbursement Rates for Health Care Establishments in France: Towards a New Allocation of Surgical Procedures?
}

\author{
Jocelyn Husser ${ }^{1}$, Olivier Guerin ${ }^{2} \&$ Daniel Bretones ${ }^{3}$ \\ ${ }^{1}$ CRECCI- IRGO/ IAE BORDEAUX IV, CRESCEM/ESCEM, France \\ ${ }^{2}$ IRGO - IAE BORDEAUX IV, France \\ ${ }^{3}$ Université Centre Val de Loire / ESCEM, France / Université PARIS I SORBONNE / PRISM, France \\ Correspondence: Daniel Bretones, Université Centre Val de Loire / ESCEM, 11 rue de l'Ancienne Comédie, \\ Poitiers, 86001 Poitiers Cedex, France. E-mail: dbretones@escem.fr
}

Received: September 6, 2012

Accepted: October 15, 2012

Online Published: November 7, 2012

doi:10.5539/ibr.v5n12p31

URL: http://dx.doi.org/10.5539/ibr.v5n12p31

\begin{abstract}
This paper describes and analyses, in the French context, the effects of the diagnosis related groups (DRGs) on surgical procedures in public and private health care establishments through an analysis of annual data extracted from the PMSI medico-administrative computerised database programme for the years 2005 and 2008. A statistical analysis conducted at a national level on surgical GHMs (homogeneous groups of patients) shows that there is no such effect in the choice of the type of group (with or without CAM complications and associated morbidities) by health care establishments. However, the study reveals an increase in coding, irrespective of the sector (private or public), since the implementation of the DRGs for the same homogeneous groups of patients. This research presents the originality of measuring the effects of the DRGs on the surgical activity of health care establishments within the French context by using a significant quantitative database. To our knowledge, this is the first research in this field of comparison between the public and private establishments financing since the implementation of the DRGs in 2005.
\end{abstract}

Keywords: DRGs (diagnosis related groups), Incentives, GHM (homogeneous groups of patients), CAM (complications and associated morbidities), activity development, coding

\section{Introduction}

In order to encourage health care establishments to increase their activity and reduce waiting times for programmed surgery within the context of controlling health spending, France has followed the example of many countries, including the US and the UK, by adopting a financing method for short-stay activities in public and private hospitals based on the principle of the diagnosis related groups (DRGs) leading to specific reimbursement rates.

The implementation of the DRGs reform began in 2005 in the case of public establishments and in the case of private establishments. The order dated 25 May 2004 sets up the assessment committee for the implementation of the French DRGs implementation, which has since published two reports on the consequences of DRGs.

To be effective, the DRGs require that hospital activities be organised in the form of homogeneous groups of patients (GHM), for which the rates are established in advance at national level and directly linked to average costs relating to GHMs. The classification of GHM hospital stays came into force in France in 1982 as part of the PMSI (Medical administrative computerised database programme) and is directly inspired by the American diagnosis related groups.

This paper aims at a better understanding, in the French context, the DRGs effects on the surgical activities of public and private health care establishments through an analysis of data extracted from the PMSI medico-administrative computerised database system in 2005 and 2008.

In the context of our research, the issue deals with the possible rejection by health care establishments, especially clinics, of certain GHMs (homogeneous groups of patients) deemed not sufficiently profitable due to unattractive rates. The determining of reimbursement's rates depends on a prior assessment of costs entering into the 
composition of a GHM. In the event where some costs might be poorly or insufficiently estimated or considered when establishing said rates any establishment which would exclude this type of GHM might be creating an additional value Keeler (1990). Lynk (2001) showed that the variation in patients within the same GHM has a genuine impact on costs: so-called intra-GHM variations explain around $50 \%$ of cost variations between establishments and it is the most severe GHMs that present the greatest variations in intra-GHM costs.

The research in hand presents the originality of measuring the effects of the DRGs on the surgical activity of health care establishments within the French context by using a significant quantitative database. To our knowledge, this is the first research in this field of comparison between the public and private establishments financing since the implementation of the DRGs in 2005.

In an effort to better grasp this specific context, a review of the existing literature on the DRGs system is presented. The advantages as well as the potential negative effects are scrutinized. An appraisal of the DRGs system is presented along with the different research questions raised.

The methodology used is introduced with the main results initially obtained. Finally, the possible contributions and improvements from this research are discussed.

\section{Literature Review}

The advantages and drawbacks of the DRGs rates have been widely debated both in professional and academic circles; Cash, Grignon and Polton (2003); Renaud (2009); and De Pouvourville (2009).

Among the advantages, therefore, it is possible to see that DRGs help to:

- Establish a link between health care production and financing;

- Make players accountable by encouraging them to increase their efficiency or otherwise be penalised by deficits. In effect, with the implementation of the estimate of revenue and expenditure, deficits are charged directly to the establishment's working capital, thus reducing its investment possibilities.

- Encourage rate harmonisation between the public and private sector;

- Enhance the development of management control tools (knowledge of costs).

However, the literature obtained, in particular, from foreign sources highlights both real and potential risks relating to the DRGs system:

- Illegitimate reduction in length of stays;

- Patient selection process to avoid the most severe cases;

- Coding effect (over coding of patient diagnostics);

- Tendency for hospitals to specialise in lucrative activities;

- Tendency for patients to be transferred to units not operating the DRGs system.

The major feature of the French DRGs reimbursement system, and indeed that of its American counterpart, the Prospective Payment System (PPS) by DRGs instituted by Medicare in 1983, is that it is exactly what it says, a prospective payment system not without some power according to the modelling conducted by Crainich, Leleu and Mauléon (2009).

The power of a payment system may be measured by the savings made, which the health care establishments are able to retain (Wennbero, McPherson \& Caper, 1984).

As Cash et al. (2003) explain in their comments of the article published by Newhouse (2003), "a remuneration system founded on the reimbursement of officially recorded costs, which used to be the adopted hospital financing method prior to the introduction of the DRGs system, is a system where such power is, in effect, nil. The hospital studied keeps none of the savings it makes and, conversely, its excess costs are offset".

In order to encourage hospitals to be more efficient, governments in the main western countries have been keen to increase the power of payment systems by setting up a flat-rate payment system based on knowledge of average costs in comparable cases. Some authors, such as Ma (1994), have shown that, in certain circumstances, prospective payment systems are superior to other remuneration systems. The principal danger in the flat-rate payment system, as suggested by the economic theories advanced by Coase (1937), is that there is an incentive for health care establishments to reduce the quality of care provided within a GHM wherever it cannot be easily observed, so as to reduce their costs. Consequently, the challenge for the buyer, in this case, the French Health Insurance system, is to be in a position to assess the quality of the product supplied by the provider as mentioned by Stingre (2012) and by Guérin and Husser (2011). This obviously raises complex ethical problems for all 
partners in the DRGs chain, as suggested by Le Coz (2009).

The shortened duration of hospital stays is one of the easiest methods to implement in order to reduce costs. However, DRGs or not DRGs, medical advances, among other types of progress, have helped to noticeably reduce the duration of hospital stays over the past few years. The shortening of hospital stays helps to improve quality by reducing, for example, the risk of nosocomial infections. The question of legitimacy as regards some shortened stays is therefore raised by Or and Renaud (2009). Newhouse (2003), on the other hand, raises the problem of transfers from short stays to medium-term stays, demonstrating that the ensuing shortened hospital stay has led to a sharp increase in follow-up care and home care. Moisdon (2010) insists on the fact that the organisation of hospitals and clinics stems from a complex process wherein the duration of the stay plays a non-negligible role. At the same time, according to Moisdon (2010), adapting health care establishments to the new DRGs system cannot boil down simply to reducing the length of stays.

Other methods resulting in a reduction in the quality of care have been widely debated in existing literature. The following authors (Levaggi, Moretto \& Rebba, 2009) underline the fact that decisions dealing with investments in new technologies have indirect consequences in terms of quality in care among the different providers.

Cash (2009) nonetheless emphasises the point that it is impossible to check for any link between the DRGs system and the drop in quality, where the assessment of that quality must adhere to other procedures.

Furthermore, one consequence of the DRGs system is that it incites an increase in activity. This volume effect would appear to be positive where it results in a reduction in waiting times. However, literature on the subject underlines the risk of an increased demand for unnecessary care, which results in a loss in overall wealth for the country. Hodges and Henson (2009) nevertheless observe that the results of empirical studies seeking to measure this phenomenon are mixed.

Finally, another undesirable effect linked to the DRGs system and, generally speaking, to prospective payment systems, concerns the possibility of patient selection by health care establishments. In the American context, Hodges and Henson (2009) develop a model in which a decrease in the rate of reimbursement can lead to this type of practice. Ellis (1998) places the emphasis on patient heterogeneity within a DRG and demonstrates the fact that, within the context of a flat-rate payment system, it is worthwhile for an establishment to select low-risk patients (creaming), avoid high-risk patients (dumping) and reduce the intensity of care (skimping). Staying with the American example (Rice, Stearns \& Pathman, 1999) reach the conclusion that health care providers are often thought to select patients on the basis of the highest payment rates. As De Pouvourville (2009) explains, in the French context, the risk of dumping is limited within the public sector, but it does indeed exist in the private sector. The author notes also that the two remaining phenomena (creaming and skimping) are possibilities in both sectors.

In the French health system, the private sector plays a major role in the structuring of the health care offering. It represents for the year 2008 more than a third of cases treated according to data obtained from the PMSI MCO. With the transition to the DRGs' reimbursement rates, it is worthwhile for establishments in this sector to target the least serious patient cases and thus avoid pathologies where the degree of case-mix variation is high. Winter (2003) thus observes that public hospitals treat the most severe patients' cases in terms of pathology.

While De Pouvourville (2009) notes that establishments can abandon a range of deficit-generating services in favour of a more lucrative range of services, Nakhla (2010) envisages the ethical or professional conduct issues raised by the conception of incentive mechanisms in the DRGs' context. Cash (2009), however, suggests that some private clinics did not wait for the transition to DRGs in order to specialise in more profitable activities. The latter were already using a prospective payment system and not a global budget method as in the case of the public sector.

The above observations relating to the risk of patient selection raise a problem regarding the reliability of the classification tool used to determine rates schedules. It has been noted by (De Pouvourville, Hallais, Czernichow, 2007) that a bias can result from a poor specification of pathologies covered within a GHM (homogeneous groups of patients). Research by Or and Renaud (2009) emphasises the fact that when costs vary greatly within the same GHM, a faithful, homogeneous retranscription of that diversity in the cases treated is very difficult. Link (2001) assesses this variability at 50\% in the case of the USA.

As soon as patient distribution is no longer random, there is a risk of unfair financing for health care establishments, with hospitals attracting the most serious patient cases in situations of insufficient funding.

However, the desire to reduce heterogeneity by increasing the number of GHMs leads to a reduction in the power of the payment system, which goes against the initial objective. 
De Pouvourville (2009) points out that, in France, the adopted solution for reducing this variance is to gradually improve the GHM classification on the basis of the severity of the patient's case. The version 11 of the GHM classification took this point of view into consideration by distinguishing four levels of severity within a GHM.

Of all the GHM (780 or so for the year 2010), a great many of them demonstrate the presence or otherwise of complications or morbidities (CAM) associated with diagnosis. It is therefore possible to distinguish between GHM without CAM and GHM with CAM. Irrespective of the main diagnosis, any affection included in the CAM list increases the hospital stay and therefore the cost of the GHM. Consequently, depending on whether or not the RSS (discharge abstract) mentions a CAM, it is classified either as a GHM with CAM or one without.

The presence of complications or morbidities associated with the diagnosis is a major factor in cost increases. Thus, if we refer to Lynk (2001) "Hospitals with the most complex DRGs logically tend towards having the most costly patients".

To close our summary of the existing literature (Fetter, Shin, Freeman, Averill \& Thompson, 1980); Gilman, 2000; (Geissier, Scheller-Kreinsen, \& Quentin, 2012), we have to ask the following question: Has the transition to the DRGs' reimbursement rates accentuated the phenomenon wherein the most severe GHMs are transferred to public hospitals?

This problem may be described as follows: As the most severe GHMs seem to present the greatest variation in intra-GHM costs, are private profit-making establishments tending to neglect GHMs with CAM in favour of GHMs without CAM? Furthermore, since the introduction of DRGs in France, is it safe to say that there has been an increase in shortened hospital stays?

Finally, is it possible to observe a coding effect?

\section{Research Methodology}

In this section, we will present the characteristics of the sample, the type of data used and the results of all the statistical treatments employed.

\subsection{Characteristics of Sample and Study Data}

Since the law of 31 January 1991, public and private establishments are under an obligation to report on their activity as part of the PMSI medico-administrative computerised database programme.

This report is based on gathering a certain amount of administrative and medical information, constituting what is known as the RSS, similar to the American hospital discharge abstract. The information collected is then processed automatically so as to classify the RSS into groups (GHMs) presenting homogeneous characteristics both on a medical and cost level. The different stays classified within the same group, in effect, present similar levels of resource consumption and starting from the very first level of classification, GHMs are divided into major diagnostic categories (MDC) in accordance with medical criteria (type of affection). Irrespective of the main diagnosis, any affection included in the CAM list increases the hospital stay and therefore the cost of the GHM. Consequently, depending on whether or not the RSS (discharge abstract) mentions a CAM, it is classified either as a GHM with CAM or one without.

The French GHM classification process is inspired by the American DRGs classification developed by Robert Fetter at Yale University. The GHM manual may be downloaded (ATIH, 2012). It permits an exhaustive classification since every RSS is necessarily classified within a single GHM only (Fetter et al., 1980). The first version of the GHM classification was published in 1986. The version 11 of the GHM is currently employed in 2012.

Ultimately, the information produced by the PMSI medico-administrative computerised database programme meets two government objectives: it allows the financing of health care establishments (reimbursement rates) and the organisation of the health care offer (planning).

The data required for conducting the research is therefore extracted from the PMSI for the medicine, obstetrics and surgery disciplines. This data is available on the website of the Agency for Information on Hospital Care (ATIH, 2012).

In order to deal with our problem and ascertain whether or not there is such a thing as the DRGs effect, stays classified as surgical GHMs were chosen for analysis, observing the presence or otherwise of complications or associated morbidities by comparing the years 2005 (version 9 of the GHM classification) and 2008 (version 10 of the GHM classification). As private profit-making establishments are little concerned by medical activities, medical GHMs were not taken into account in the present research. As regards coding, those GHMs with complications or associated morbidities end in $\mathrm{W}$ and those without in $\mathrm{V}$. 
Our analysis focuses on 148 surgical GHMs ( 74 with CAM ending in $\mathrm{W}$ and 74 without CAM ending in V). The version 9 of the GHM classification was introduced in 2004 to prepare the transition to DRGs. The research is focused mainly on the years 2005 and 2008. The reasons for this choice are the following: the implementation of the DRGs in the French context occurred in 2005, which can be considered as a reference year for comparisons. The year 2008 is the last year before a new classification of the GHM took place.

The years 2009 and 2010 cannot be used because the new classification differs totally from the previous years. It is therefore impossible to compare databases with such differences and cross-references couldn't be established because the new GHMs no longer correspond to the former classification.

\subsection{Statistical Analysis}

The selection effect, followed by the coding effect (A) and the shortened stay effect (B) are being discussed.

\subsection{Methodology}

The variables under study are obtained from two paired samples, since they are measured in the same sample at regular time intervals, in this case the years 2005 and 2008.

The Wilcoxon signed rank test is used. It serves to test whether or not there is a difference between two populations. It is used to determine whether the difference between two observation pairs is positive or negative, while taking into account the extent of that difference.

\subsection{Selection and Coding Effects}

The hypothesis that it is worthwhile for the private sector, in order to avoid taking on the most severe and therefore more costly patient cases, to avoid GHMs with complications or associated morbidities may be understood via the share of activity it occupies in this type of GHM. A sharp decrease would tend to validate the hypothesis that DRGs have indeed accelerated the phenomenon.

Finally, GHMs with complications or associated morbidities being better remunerated by the Health Insurance system, health care establishments may be tempted to overcode patient diagnostics. This coding effect, about which there is very little documented evidence, is measured via the proportion of GHMs ending in W. A statistically significant increase between 2005 and 2008 would lead us to believe that DRGs do indeed encourage such a practice.

The results show that surgical activity within the 148 GHMs is fairly distributed in 2008 , while it was slightly higher in the private sector in 2005 (53.02\%); if we make a distinction on the basis of complication or associated morbidity, the result is not surprising since the public sector covers around $56 \%$ of the activity within GHMs with CAM. There is a notable lack of DRGs effect in terms of patient selection, since the portion of activity attributed to clinics within GHMs with CAM is the same in 2005 and 2008 (43\%).

On the other hand, we may observe the sharp increase in the number of grouped stays with CAM both in the public and private sectors following the DRGs' introduction (a 16\% to $21 \%$ increase in the private sector and a $24 \%$ to $28 \%$ increase in the public sector). The result is statistically significant, as there does indeed appear to be a coding effect irrespective of the type of establishment between 2005 and 2008.

Table 1. Measurement of selection and coding effects

\begin{tabular}{|c|c|c|c|c|c|c|c|c|c|c|}
\hline & \multicolumn{2}{|c|}{ Total GHM } & \multicolumn{2}{|c|}{ GHM w/o CAM } & \multicolumn{2}{|c|}{ GHM with CAM } & \multicolumn{2}{|c|}{$\begin{array}{c}\text { Coding proportion } \\
\text { CAM in } \%\end{array}$} & \multicolumn{2}{|c|}{ Result of statistical test } \\
\hline & 2005 & 2008 & 2005 & 2008 & 2005 & 2008 & 2005 & 2008 & Wilcoxon's Z & C.P.* \\
\hline Public sector stays & 825,023 & 992,455 & 615,243 & 712,165 & 196,052 & 280,29 & 25.43 & 28.24 & -5.448 & 0.000 \\
\hline Private sector stays & 931,242 & $1,026,748$ & 747,754 & 809,767 & 183,488 & 216,981 & 19.70 & 21.13 & -6.190 & 0.000 \\
\hline Total & $1,756,265$ & $2,019,203$ & $1,362,997$ & $1,521,932$ & 393,267 & 497,271 & 22.39 & 24.63 & & \\
\hline Public sector share in $\%$ & 46.98 & 49.15 & 45.14 & 46.79 & 53.34 & 56.37 & & & & \\
\hline Private sector share in $\%$ & 53.02 & 50.85 & 54.86 & 53.21 & 46.66 & 43.63 & & & & \\
\hline
\end{tabular}

Note: ${ }^{*}$ C.P. $=$ Critical Probability.

\subsection{Shortened Stay Effect}

The decrease in the duration of hospital stays has remained a constant factor for several years. Historically, stays are shorter in the private sector.

Has the transition to DRGs accentuated the phenomenon, as literature on the subject suggests? 
Table 2. Measurement of shortened stay effect

\begin{tabular}{|c|c|c|c|c|c|c|}
\hline & \multicolumn{2}{|c|}{ Total GHM } & \multicolumn{2}{|c|}{ GHM with CAM } & \multicolumn{2}{|l|}{ Result of statistical test } \\
\hline & 2005 & 2008 & 2005 & 2008 & Wilcoxon's Z GHM with CAM & C.P* \\
\hline Duration of public sector stay & 10.98 & 10.54 & 14.37 & 14 & -6.522 & 0.000 \\
\hline Duration of private sector stay & 8.14 & 8.16 & 9.98 & 10.42 & -4.771 & 0.000 \\
\hline
\end{tabular}

Note: ${ }^{*}$ C.P. $=$ Critical Probability.

The results show that the stay duration continues to decrease in health care establishments.

Logically speaking, the decrease is more significant when one takes all GHMs into account; it is, in effect, more questionable to reduce the stay when the pathology is severe. Nevertheless, the significance is strong in both cases. The continuous decrease in the duration of hospital stays is generated by the constant decrease of income for long stays. As a matter of fact, the DRGs policy has consisted of allocating a constant decrease of daily income for long stays over the 8 past years. This decrease appears to be a well-suited response to economic pressure implemented by the French Government.

\section{Conclusions}

There is a relatively large amount of academic and professional literature in France and abroad dealing with the possible consequences of the DRGs on the activity of health care establishments. Thus, research was done to study the relationship between DRGs and patients who consume substantial hospital resources (Cots et al., 2004), and very detailed studies were also conducted to examine the link between DRGs and the cost of treatment of specific diseases (Evers et al., 2002). For instance, the authors consider the case of stroke patients, and, according to them, the main question is whether the current DRG classification system can provide a satisfactory prediction of the variance of costs.

However, for the moment there are few longitudinal empirical studies to support the hypotheses formulated by the various researchers.

The purpose of this research was to partly fill this gap by focusing on three potential adverse effects of the DRGs as identified by researchers, namely coding, patient selection and shortened stays, based on an analysis of the years 2005 and 2008.

The statistical analysis presented and relating to surgical GHMs shows that there are no DRGs effects in the choice of GHM type (with or without CAM) exercised by health care establishments. The private sector does not neglect the most severe GHMs only to specialise in less costly ones.

However, since the transition to the DRGs, we may observe an increase in coding in the case of surgical GHMs, irrespective of sector. This coding effect compels us to look at the ethical considerations facing players in the DRGs chain daily: not only doctors, but also the Medical Information Departments (MIDs) and retro-coding departments. This coding effect is a well-suited response to environmental pressure. It allows public and private sector to adjust its expense to a true and fair economic income generated by daily activities.

Finally, there is a continued decrease in hospital stays, although it is very difficult, given the data and results in our possession, to specifically attribute that decrease to DRGs.

Furthermore, it would be interesting in subsequent research to deepen our analysis of the points raised by focusing on specific procedures, while taking account the size of the health care establishment and analysing the data for the intermediate years: 2006 and 2007.

\section{References}

ATIH. (2012, September 6). Retrieve from http://www.atih.sante.fr/.

Cash, R. (2009). La T2A sous le feu des critiques. Editorial de la lettre de la revue Finances Hospitalières.

Cash, R., Grignon, M., \& Polton, D. (2003). L'expérience américaine et la réforme de la tarification à l'activité. Commentaire de l'article de J. Newhouse. Economie publique, 13.

Coase, R. H. (1937). The Nature of the Firm Paris. Economica, p.157. http://dx.doi.org/10.1111/j.1468-0335.1937.tb00002.x

Cots, F., Mercade, L., Castells, X., \& Salvador, X. (2004). Relationship between Hospital Structural Level and length of stay outliers: Implications for hospital payment systems. Health Policy, 68(2), 159-168. http://dx.doi.org/10.1016/j.healthpol.2003.09.004

Crainich, D., Leleu, H., \& Mauleon, A. (2009). Impact du passage à la tarification à l'activité. Revue 
Economique, 60(2), 23-34. http://dx.doi.org/10.3917/reco.602.0471

De Pouvourville, G. (2009). Les hôpitaux français face au paiement prospectif au cas: la mise en oeuvre de la tarification à l'activité. Revue économique, 60(2), 457-470. http://dx.doi.org/10.3917/reco.602.0457

De Pouvourville, G., Hallais, C., \& Czernichow, P. (2007). Gravité des malades et surcoûts dans les hôpitaux de référence. Journal d'économie médicale, 25(3), 177-187.

Ellis, R. P. (1998). Creaming, skimping and dumping: provider competition on the intensive and extensive margins. Journal of Health Economics, 17. http://dx.doi.org/10.1016/S0167-6296(97)00042-8

Evers, S., Voss, G., Nieman, F., Ament, A., Groot, T., Looder, J., \& Boreas, A. (2002). Predicting the cost of hospital stay for stroke patients: the use of diagnosis related groups. Health Policy, 61(1), 21-42. http://dx.doi.org/10.1016/S0168-8510(01)00219-6

Fetter, R., Shin, Y., Freeman, J., Averill, R., \& Thompson, J. (1980). Case Mix definition by Diagnosis-Related-Groups. Medical Care, 18(2), 1-53.

Geissier, A., Scheller-Kreinsen, D., \& Quentin, W. (2012). Do Diagnosis-Related Groups appropriately explain variations in costs and length of stay of hip replacement? A comparative assessment of DRG systems across 10 European Countries. Health Economics, 21(2), 103-115. http://dx.doi.org/10.1002/hec.2848

Gilman, B. H. (2000). Hospital response to DRG refinements: the impact of multiple reimbursement incentives on inpatient length of stay. Health Economics, 9(4), 277-294. http://dx.doi.org/10.1002/1099-1050(200006)9:4<277::AID-HEC513>3.0.CO;2-1

Guérin, O., \& Husser, J. (2011). Les effets incitatifs de la T2A pour les établissements de soins: vers une nouvelle répartition des actes chirurgicaux. Vie et Sciences Economiques, 189(3), 12-22. http://dx.doi.org/10.3917/vse.189.0012

Hodges, H., \& Henson, S. E. (2009). Medical reimbursements and patient selection by physicians: a capital-theoretic approach. Atlantic Economic Journal, 37. http://dx.doi.org/10.1007/s11293-009-9193-7

Keeler, E. B. (1990). What proportion of hospital costs differences is justifiable? Journal of Health Economics, 9, 359-365. http://dx.doi.org/10.1016/0167-6296(90)90051-4

Lecoz, P. (2009). L'exigence éthique et la tarification à l'activité à l'hôpital. Revue de philosophie économique, 10(1), 34-56.

Levaggi, R., Moretto, M., \& Rebba, V. (2009). Investment decisions in hospital technology care when physicians are devoted workers. Social Science Research Network Electronic Paper Collection.

Lynk, W. J. (2001). One DRG, One Price? The effect of patient condition on price variation within DRGS and across hospitals. International Journal of Health Care Finance and Economics, 1(2), 111-137. http://dx.doi.org/10.1023/A:1012874527253

Ma, C. T. A. (1994). Health care payment systems: cost and quality incentives. Journal of Economics \& Management Strategy, 3. http://dx.doi.org/10.1111/j.1430-9134.1994.00093.x

Moisdon, J. C. (2010). L'évaluation du changement organisationnel par l'approche de la recherche intervention, l'exemple des impacts de la T2A. Revue Française des Affaires Sociales, n 1, 12-29.

Nakhla, M. (2010). Conception et mécanismes de rémunération variable des médecins et incitation au développement de l'activité. Journal d'économie médicale, 28(3-4), 127-140.

Newhouse, J. (2003). Reimbursing for health care services. Economie publique, 13.

Or, Z., \& Renaud, T. (2009). Principes et enjeux de la tarification à l'activité à l'hôpital (T2A): Enseignements de la théorie économique et des expériences étrangères. Document de travail IRDES, n²1, 1-22. http://www.irdes.fr/EspaceRecherche/DocumentsDeTravail/DT23PrincipEnjeuxTarificActiviteHopital.pdf

Rice, T., Stearns, S., \& Pathman, D. (1999). A tale of two bounties: the impact of competing fees on physician behavior. Journal of Health Politics, Policy and Law, 6(24), 1307-1330.

Stingre, D. (2012). Le service public hospitalier, PUF, 127 p. (Que sais-je ?).

Wennbero, J., McPherson, K., \& Caper, P. (1984). Will payment based on diagnosis-related groups control hospital costs? The New England Journal of Medicine, 311(5), 295-300. http://dx.doi.org/10.1056/NEJM198408023110505

Winter, A. (2003). Comparing the mix of patients in various outpatient surgery settings. Health Affairs, 22(6). http://dx.doi.org/10.1377/hlthaff.22.6.68 